\title{
Implementation of the lean ergonomics approach to process performance improvement
}

\section{Implementación del enfoque lean ergonomics para la mejora de desempeño de procesos}

\author{
LÓPEZ-ACOSTA, Mauricio*†, GARCÍA-VILCHES, Susana, VELARDE-CANTÚ, José Manuel and \\ CHACARA-MONTES, Allán
}

Instituto Tecnológico de Sonora

ID $1^{\text {st }}$ Author: Mauricio, López-Acosta / ORC ID: 0000-0003-3728-9576, Researcher ID Thomson: X-4274-2019

ID $1^{\text {st }}$ Coauthor: Susana, García-Vilches / ORC ID: 0000-0002-5476-2890

ID $2^{\text {nd }}$ Coauthor: José Manuel, Velarde-Cantú / ORC ID: 0000-0002-1697-8551

ID $3^{\text {rd }}$ Coauthor: Allán, Chacara-Montes / ORC ID: 0000-0002-0567-0017

DOI: $10.35429 /$ JMPC.2019.15.5.10.21

Received March 10, 2019; Accepted June 30, 2019

\begin{abstract}
Actually market is subject to constant change which forces organizations to innovate with new strategies that provide greater productivity to maintain a competitive advantage, one of the flexible tools used are Lean systems. However, in most of the improvements registered in these systems, the nonergonomic elements have not been considered as waste, which have high costs for companies. This document presents an approach to integrating Lean systems with Ergonomics, the main tools used were Value Stream Mapping, SIPOC, Kaizen, REBA Method and NIOSH. As a result, a risk identification was obtained in $86 \%$ of the 26 activities of three processes analyzed, mainly by postures, manual lifting of loads and repetitiveness, with the improvements developed, the 25 controlled risks were reduced high to medium or low and obtained an average reduction of $32 \%$ in the cycle time of operations, making each process more efficient.
\end{abstract}

Lean Manufacturing, Ergonomics. Improvement of processes

\begin{abstract}
Resumen
Los constantes cambios en el mercado obligan a las organizaciones a innovar con nuevas estrategias que brinden mayor productividad para mantener una ventaja competitiva, una de las herramientas ampliamente utilizadas son los sistemas Lean. Sin embargo, en la mayoría de las mejoras registradas en estos sistemas no se han considerado los elementos disergonómicos como un desperdicio, los cuales generan altos costos para las empresas. En este documento se presenta un enfoque de integración de los sistemas Lean con la Ergonomía, las principales herramientas utilizadas fueron Value Stream Mapping, SIPOC, Kaizen, Método REBA y NIOSH. Como resultado se obtuvo una identificación de riesgos en el $86 \%$ de las 26 actividades de tres procesos analizados, principalmente por posturas, levantamiento manual de cargas y repetitividad, con las mejoras desarrolladas se lograron reducir los 25 riesgos considerados altos a medio o bajos y se obtuvo una reducción promedio del $32 \%$ en el tiempo de ciclo de las operaciones, haciendo más eficiente cada proceso.
\end{abstract}

Manufactura Esbelta, Ergonomía, Mejora de Procesos

Citation: LÓPEZ-ACOSTA, Mauricio, GARCÍA-VILCHES, Susana, VELARDE-CANTÚ, José Manuel and CHACARAMONTES, Allán. Implementation of the lean ergonomics approach to process performance improvement. Journal of Microfinance Planning and Control. 2019, 5-15: 10-21

\footnotetext{
* Correspondence to Author (email: Mauricio.lopez@itson.edu.mx)

$\uparrow$ Researcher contributing first author.
} 


\section{Introduction}

The model on the integration of ergonomics and lean manufacturing systems based on the various tools has been presented in various organizations, (Srinivasa and Malay, 2016). While current perspectives consider lean manufacturing as a socio-technical system according to Cullinane, Bosak, Flood, and Demerouti, (2014), with a focus beyond workshop skills to reflect a broader management philosophy that incorporates tools and Human resource practices. Monroe, Fick, \& Joshi, (2012), adds that a cost-saving analysis can be performed to demonstrate the impact that ergonomic elements can have on a project specifically increasing productivity and quality can be traced and quantified as a tracking metric.

A common tool to analyze and improve production processes is the Value Stream Mapping (VSM), it is a lean tool that aims to reduce waste. Integrating ergonomics into VSM allows simultaneous consideration of the production system's performance and physical risk factors for the development of skeletal muscle disorders in the manufacturing industry, (Jarebrant, et al., 2015). Lean Ergonomics improves the factors of the work environment in a "Value Stream Mapping" tool of lean manufacturing by identifying risks in the workstation where it evaluates each work activity of the process, (Kasper, 2017).

Prins (2004) explains that through the use of lean strategies with ergonomic principles, safety and job satisfaction tools, both workers and the general process can benefit. Mulyati, Suharno and Muharom, (2015) indicate that the combination of lean thinking and ergonomics are the result of a system where not only the worker is as efficient, but also safe and comfortable while trying to produce the best possible product. Cirjaliu \& Draghici, (2016) mention that the differences between Lean theory and the needs of employees for feedback and participation directly with the company, helps reduce stress in lean manufacturing through misunderstanding, collaboration internal between employees and managers. In 2015 Dos Santos, Vieira, and Balbinotti developed an investigation within an automobile vehicle production factory, where Lean Manufacturing tools were implemented adding ergonomic evaluation and working conditions.
In this case, the reduction between the periods from 2013 to 2015 was analyzed until the month of March, a reduction of $23 \%$ was obtained compared to the performance in the company. In the work presented by Mulyati, Suharno and Muharom (2015), they applied the lean ergonomics philosophy in a cookie plant in the Yogyakarta region, Indonesia, where ergonomic waste was identified; the most important was the movement that must be resolved immediately with improvements in the vertical and horizontal design.

The great growth in manufacturing has created a lot of economic, environmental and social problems around the world generating the rapid elimination of local waste, (Kumar, 2014). Companies are looking for solutions to increase flexibility and reduce delivery time, the global market is forcing companies to find new ways to reduce costs while maintaining or increasing their quality level. However, Márquez, (2012) mentions that ergonomic principles continue to be second. Solís and Madriz, (2009) complement that many of the risk factors such as strength, repetition and inappropriate postures are the result of an inefficient and poor design of work environments and bad practices in them.

Kim (2017) mentions that when Lean tools are implemented effectively, a culture of worker participation and empowerment is created and a positive work environment is established in which changes in the workplace are expected and accepted. Certainly, the improvement in the work environment achieved by the slender manufacturing is desirable, because through the organization and description of the activities to be carried out, there is a greater control of movements and flow of materials / people in the work stations, which eventually reduces workers' exposure to unplanned injuries and accidents, (Peralta et al, 2017).

According to Yang, Hong, and Modi, (2011), lean manufacturing is complemented by other tools that help balance lines, supply flow of parts and products, identify the process value chain, without neglecting safety and ergonomics. Morse in 2014 concludes that the need for rapid employee participation to adapt and meet demands, the right combination of security, and satisfaction to avoid conflicts. 


\section{Methodology}

Subjects of study

The present study is carried out in a pork processing company, specifically in the area of processing within the processes of Smoked Sausage, Sausage Mixing and Sausage, Brine. It is a company dedicated to processing and marketing pork and its derivatives nationally and internationally, has a capacity of 500 tons of monthly production, has 165 people, the main customers are national.

\section{Process}

Preparation of the Current VSM: at this stage the operations are analyzed through the Value Stream Mapping VSM tool to know the current situation of the processes, where the following elements should be considered:

Process Diagram Elaboration. Analyze the supply chain in detail for each process using the SIPOC Diagram.

Ergonomic Risk Identification. Identify risks in each of the process operations using the BRIEF / BEST Method, determining their risk condition.

Ergonomic Risk Assessment. Evaluate workstation activities using ergonomic methods according to the results of the risk identification in order to define redesign options that reduce risk and obtain acceptable levels of exposure for the worker.

Development of the future VSM. At this stage, ergonomic improvements will be integrated into a future VSM to compare the previous efficiency with the current one in the operations of the processes and the assessment of the ergonomic risks found, it should be considered:

Design of Improvement Proposals. Establish improvement actions using Lean tools to reduce waste that occurs during processes, considering ergonomic conditions and factors. Ergonomic Risk Assessment. Evaluate the activities in the work stations with the implementation of improvements to verify changes as interaction between the human being and the elements used in the operations of the process.
Design of a control plan. As a last stage, a control plan for the assurance of continuous improvement should be developed, establishing a matrix of priorities and responsibilities, structuring the design, selection and control methods to reduce process variation.

Materials

$\begin{array}{ll}- & \text { Nordic Questionnaire } \\ - & \text { BRIEF / BEST questionnaire } \\ - & \text { Photographic camera } \\ - & \text { Fields of evaluation methods } \\ - & \text { Ergo Soft Pro 4.0 software } \\ - & \text { Microsoft Visio Professional } 2016\end{array}$

\section{Results}

The SIPOC tool was used to visualize the study area in detail and learn about the operations involved in each process, see tables 1-3. Adding elements such as activities to be carried out, the person in charge of said activity, who provides it, specifying the entrance of the process, its exit and the client, resulting in the analysis of the current situation of each operation during its process and identify the personnel that works, which benefits the next stage of this study, facilitating its identification and risk assessment.

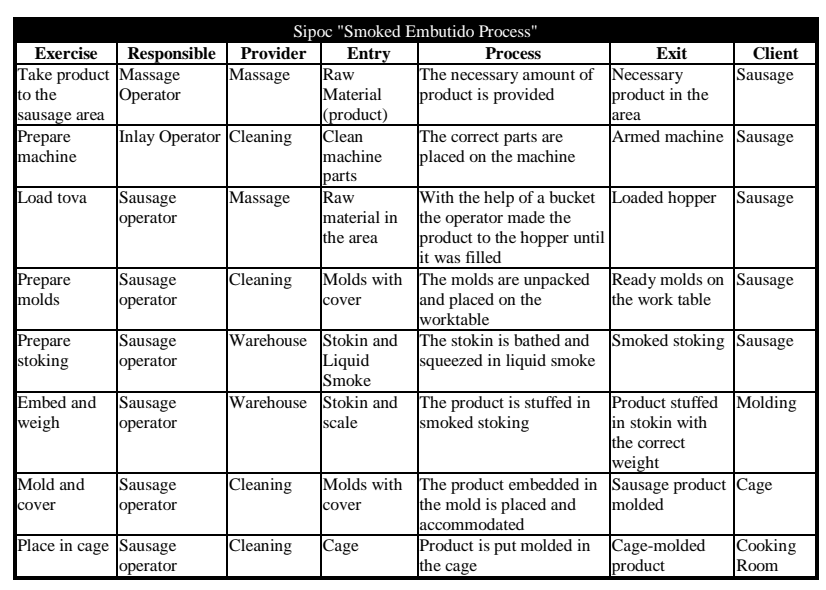

Table 1 SIPOC of the Smoked Sausage process

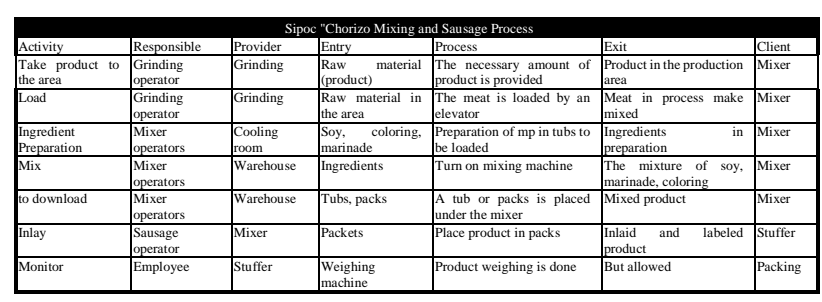

Table 2 SIPOC of the Chorizo Mixing and Sausage process 


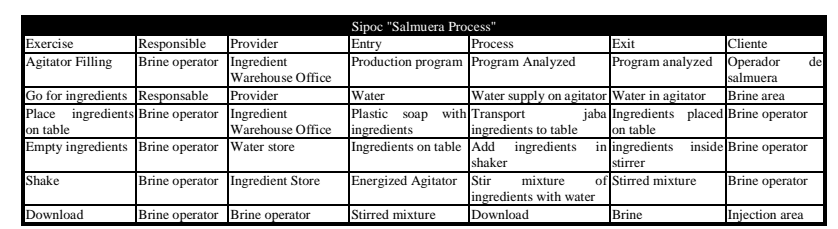

Table 3 SIPOC of the Brine process

Risk identification was carried out using the BRIEF / BEST method. The Brief / Best method was of great support in this study to identify the ergonomic risks that exist in each activity of the process and the part of the human body that is exposed to an injury and / or occupational disease, in addition in this survey they are considered physical pressures such as vibrations, low temperatures, problems with gloves etc. With the application of this method the identification of risks of each operation was obtained by process, where the anatomical regions of the human body exposed to suffer an injury or disease is: neck, back and hands.

Table 4 shows that in the Smoked Sausage process an ergonomic evaluation is required in all its operations except number 1 , in Mixing and Chorizo sausage in most of its activities with the exception of operation 1 and 12 because it is under the level of risk, and for the last in the brine process in all but the initial activity.

\begin{tabular}{|l|r|r|l|}
\hline \multicolumn{1}{|c}{ Process } & \multicolumn{1}{c|}{ Operations } & Risk value & Risk level \\
\hline \multirow{3}{*}{\begin{tabular}{l} 
Smoked Sausage \\
\cline { 2 - 4 }
\end{tabular}} & $3,4,5$ & $>9$ & Low \\
\cline { 2 - 4 } & $2,7,6$ & $<30$ & Medium \\
\hline \multirow{2}{*}{$\begin{array}{l}\text { Sausage Mix and } \\
\text { Sausage }\end{array}$} & 3,12 & $>9$ & Low \\
\cline { 2 - 4 } & $1,2,5,6,7,8,9,10,11$ & $10-29$ & Medium \\
\cline { 2 - 4 } Brine & 4 & $<30$ & High \\
\cline { 2 - 4 } & 1 & $>9$ & Low \\
\cline { 2 - 4 } & $2,3,5$ & $10-29$ & Medium \\
\hline
\end{tabular}

Table 4 Risk Identification BRIEF / BEST Method of the Processed are

According to the results of the risk identification, the ergonomic methods to be used were determined, in the processes of Smoked Sausage and Brine, its main activities of suffering any injury is according to the Brief / Brest is due to improper postures and manual handling of loads, evaluating with REBA and NIOSH Method, for the process of Mixing and Sausage Sausage also identified risks by manual handling of load but with displacement and repetitive movements for them the MAC method and erg / IBV will be used respectively. To carry out this stage, a video was taken of the entire cycle of each process to determine the positions to be evaluated.
Risk assessment process Smoked Sausage. This process has 6 operations: Activities 1, 2, 4, 5 and 6 were high-risk identification due to inappropriate postures, so an ergonomic evaluation was carried out with the REBA Method. The positions are shown in Annex 1.

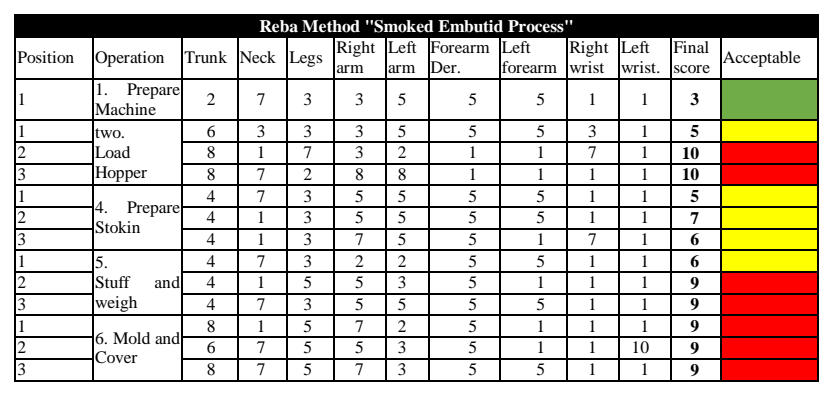

Table 5 Ergonomic evaluation of the Smoked Sausage process with REBA Method

The results of the evaluation using the NIOSH Method are the following: in the operation of preparing molds, an index of 0.66 was obtained for the origin, which indicates that the level of risk is low, however, for the destination, the horizontal position exceeds the centimeters allowed by the method, so for the purposes of the calculation the maximum amount allowed by the method was taken as a reference.

Therefore, it is obtained that there is a high risk, from the ergonomic point of view this task must be modified. For the activity to accommodate in a cage, an index of 0.97 for the origin and of 1.38 for the destination was obtained, which means that there is low risk for the origin and a moderate risk for the destination when carrying out the activity, however, the operators they may suffer injuries if they continue to do so in the same way, so it is convenient that tasks of this type must be redesigned or assigned to selected workers under control, see Table 6 .

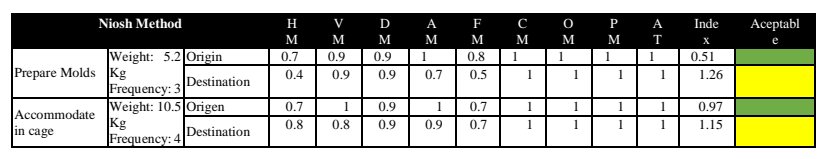

Table 6 Ergonomic evaluation of the Smoked Sausage process with NIOSH Method 
Chorizo Mix and Sausage process risk assessment. This is one of the processes with more operations for the manufacture of its products has 12 activities which were applied different ergonomic methods such as the REBA Method to evaluate postures, ERGO / IVB repetitive movements, and the MAC Method for manual handling of loads with movement, taking as reference the following parts of the human body: neck, legs, forearm, wrist, trunk and other factors such as grip and load weight, in the Annex 2 the postures are shown, the postures evaluated with the REBA method are shown.

Table 7 shows the results according to the REBA Method for this process were in operations 1, 4, 9, 10 and 11 high risk, immediate action is recommended, operations 2, 5, 6, 7 and 12 is risk It is necessary to take preventive measures, activities 3, 6 and 8 are of negligible low risk and do not require analysis or preventive action.

During the identification of risks of operations with repetitive movements, such as the Embedding and Monitoring activity, this analysis was carried out using the ERGO / IVB Repetitiveness Method, generating immediate action results because they are high risk, causing the Be exposed to injuries in the future or suffer from a work-related illness. The following graph represents the color of red is the score that is 4 very high, see table 8

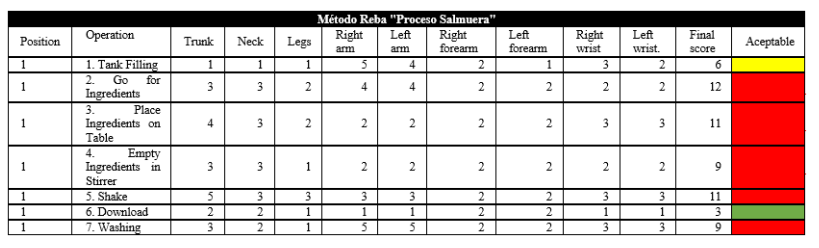

Table 7 Ergonomic evaluation of the Sausage Mixing and Sausage process with REBA Method

\begin{tabular}{|l|l|l|l|l|}
\hline ERGO / IBV Method & \multicolumn{2}{l|}{ Inlay } & Monitoring \\
\hline Factors & Punctuation & Acceptable & Punctuation & Aceptable \\
\hline Exposition (\%) & 100 & 100 & \\
\hline Arms repetitiveness & 57 & 57 & \\
\hline Repetitive Hands & 50 & & 50 & \\
\hline CP Neck Risk & IV & IV & \\
\hline MP Neck Risk & IV & IV & \\
\hline LP Neck Risk & IV & & IV & \\
\hline Hand Risk & IV & & IV & \\
\hline
\end{tabular}

Table 8 Ergonomic evaluation with the ERGO / IVB Method of the Sausage Mixing and Sausage process

Manual handling of loads was assessed using the MAC Method, obtaining a 14-point record, which according to the conditions represents a high risk and immediate actions during activities 1, 2, 3, 6, 7 and 10 see table 9 .

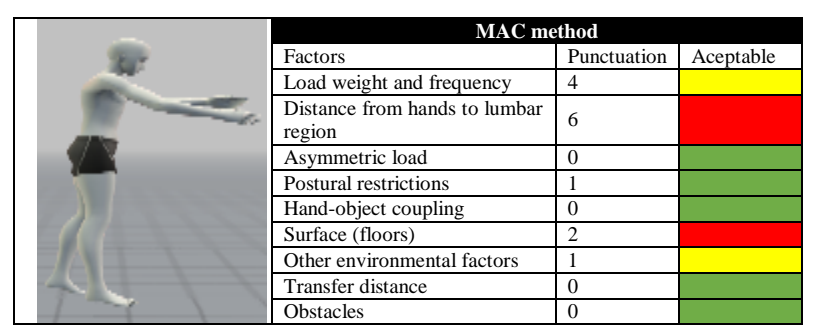

Table 9 Ergonomic evaluation with the MAC Method of the Sausage Mixing and Sausage process

Risk evaluation process Brine. The ergonomic risks of the 7 activities of the brine process were evaluated, in order to raise awareness of the level of risk, taking into account the positions and handling of operator loads, see Annex 3. With the application of the REBA Method they obtained the following results: with a level of Medium risk, only operation 1 what needs to be taken, High risk activities 2, 3, 4, 5, and 7 being urgent corrective action to improve the positions of the operator, and Low risk only operation 6, see table 10.

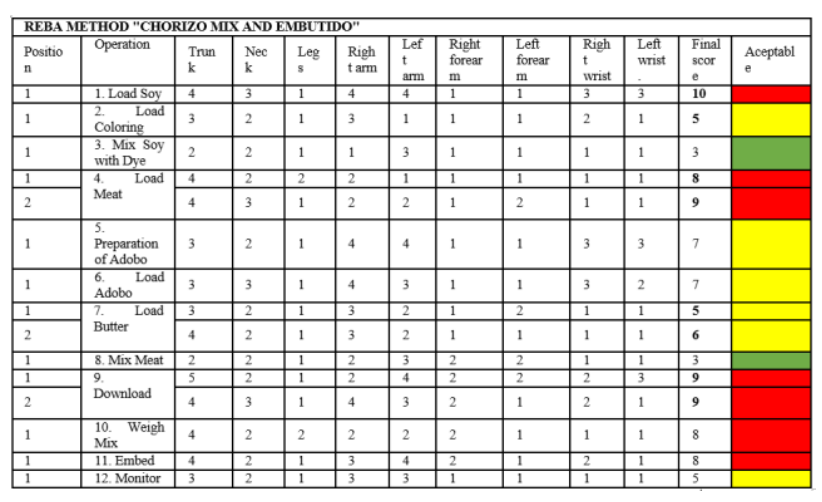

Table 10 Ergonomic evaluation with the REBA Method of the Brine process

For the evaluation of cargo handling, the NIOSH method was used; 3 activities were identified where the operator performs load lifting tasks, where all operations have a high risk; Immediate action is required. (see table 11).

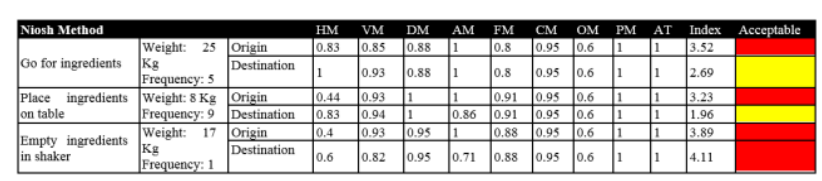

Table 11 Ergonomic evaluation with the NIOSH Method of the Brine process
LÓPEZ-ACOSTA, Mauricio, GARCÍA-VILCHES, Susana, VELARDE-CANTÚ, José Manuel and CHACARA-MONTES, Allán. Implementation of the lean ergonomics approach to process performance improvement. Journal of Microfinance Planning and Control. 2019 


\section{Value flow map of the Processed Area}

The VSM represents the current situation processed area divided into the processes of Smoked Sausage, Mix and Sausage Sausage, and Brine; which indicates the way in which the process flows, operating times, requirements, inventories, pieces per batch and the flow of customer and supplier information. It also shows the result of the ergonomic evaluation for each process and operation indicating the level of risk of each posture evaluated and method used, using a circle and boxes of red, yellow and green.

The manufacturing times of the processes are the following in Smoked Sausage of $147.37 \mathrm{~min}$ for the production of 1 lot corresponding to 137 pcs of the stubborn product, the Chorizo Mixing and Sausage process is $277 \mathrm{~min}$ per batch in pieces are 2450 of the product ranch sausage, and finally in brine for each batch 300 liters is produced to supply the processes of the processed area, see figure 1 .

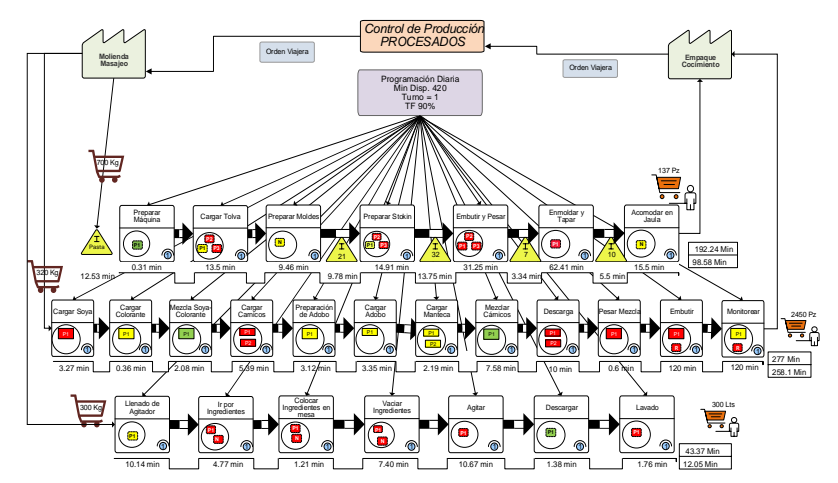

Figure 1 Current VSM with Ergonomic Evaluation of the Processed Area

Source: Self Made

\section{Improvement proposals design}

The correct positions that operators must perform to reduce or eliminate the risk during their activities were established, for this purpose they propose to use some Lean tools to eliminate the waste generated in the process such as unnecessary movements.
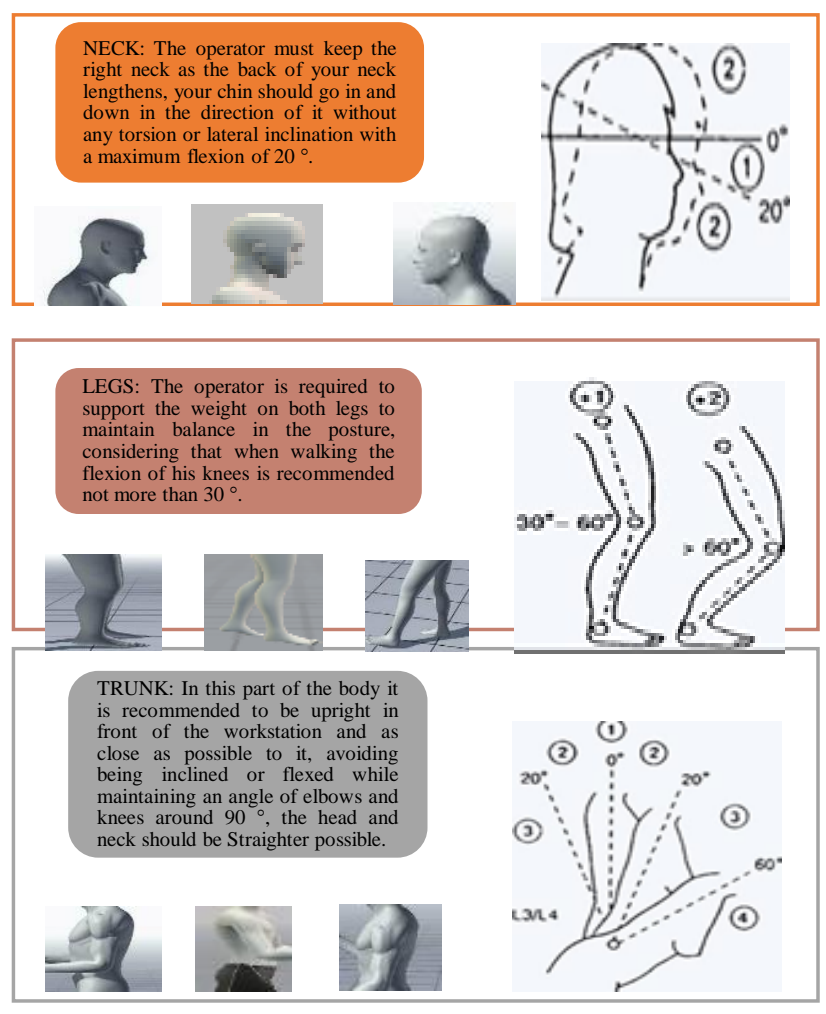

Figure 2 Proposals for positions Evaluated with the REBA Group a Method

In group $\mathrm{A}$, the anatomical region of the trunk predominates with a high score and with a greater risk factor than the other parts of the body, it is necessary for the operator to adopt neutral positions, the position of the spine must retain its natural curvatures and avoid turning and sudden changes in position, in addition to having working conditions according to their physical dimensions and ability to increase their productivity avoiding any work-related injury or illness.

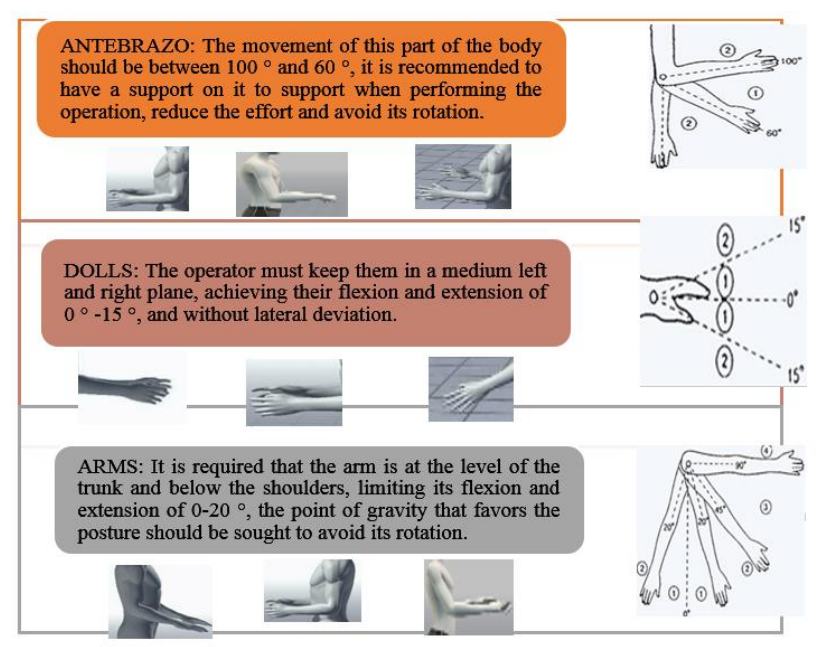

Figure 3 Proposals of positions Evaluated with the REBA Group B Method 
In group B the arms are mainly exposed to be damaged, so it is recommended that the tool to be used is close to the operator's body and better yet have some auxiliary element that helps to counteract the weight of the tool.

Design of Proposals for improvement in Cargo Handling Postures. In the processes of Smoked Sausage and Brine, the NIOSH method was used because the manipulation of the weight is manual (see figure 4), while for MACL Sausage Mixing and Sausage the MAC Method was used due to the fact that there is movement when loading the weight during its operations, to improve the position of the worker, the design proposals must be applied in the equipment that transports the material, in this way the operator automatically changes his posture.

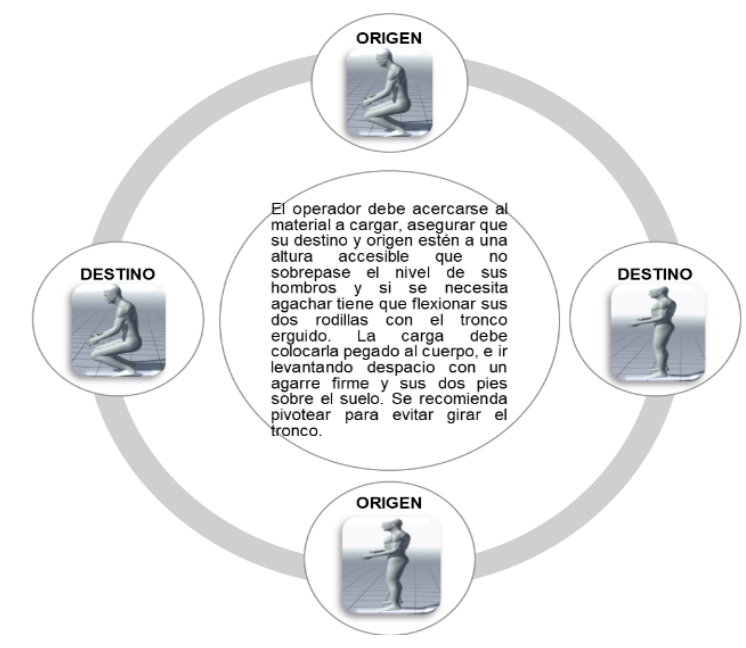

Figure 4 Proposals of positions Evaluated with the NIOSH Method

In the Smoked Sausage process it is proposed: Establish a Poka Yoke that helps to standardize the distance to which the materials used during the process should be.

A worktable with adjustable height, such as the one you already have, but a range that the operator can move it to a higher level because the current one can only decrease its height and it is at a very low level to the person who is in the work station. For the Filling in Hopper it is proposed to use the same mechanism of other processes for the filling of hoppers by means of a vertical elevator
Chorizo Mixing and Sausage Process proposes the following: A supermarket at the beginning of the process and after preparation of marinade with the purpose of eliminating some operations and reducing its time, is to keep the materials in containers, and in turn place kanban of withdrawal that indicates to the warehouse area and supplies the process of the raw material that is needed. Acquiring a stainless-steel shovel with the measures of 500-700 grams, $10 \times 10 \times 70$ $\mathrm{cm}$ will be used for the Unloading activity, thus reducing the operation time and eliminating the operator's risk posture.

To improve the Embedding operation where risk factors due to repetitive movements were found, it is recommended that the equipment be put into automatic mode and in this way the operator can engage in another activity and eliminate his risky posture. Another proposal is to handle the loads with a utility cart to reduce the times and improve the evaluation of the MAC Method and the risk to the operator for moving the material.

\section{Brine Process is proposed:}

Install an intercom, in the brine area since before the discharge is performed, the operator has to communicate with the operator of the injection area through an intercom that is installed in a neighboring area to the brine called the area of weighing ingredients. Where the operator has to leave to that place traveling a distance of 15 meters. Performing this improvement will reduce the time interval between agitation and discharge activities where a dead time of 6.04 minutes is averaged.

Improvement Analysis of the Smoked Sausage Process. The efficiency of the process operations was calculated obtaining a time reduction of 76.42 minutes, which in percentage represents 39.7 for a batch of 137 pieces, see table 12 .

\begin{tabular}{|l|l|l|}
\cline { 2 - 3 } \multicolumn{1}{c|}{} & \multicolumn{2}{|l|}{ Efficiency } \\
\cline { 2 - 3 } \multicolumn{1}{c|}{} & Min & Pieces \\
\hline Current & 192.24 & 137 \\
\hline Improved & 115.82 & 137 \\
\hline Saving & 76.42 & \multicolumn{1}{|c}{} \\
\cline { 2 - 2 } & $\mathbf{3 9 . 7 \%}$ & \multicolumn{1}{|c}{} \\
\end{tabular}

Table 12 Efficiency Improvement in the Smoked Sausage Process. 
The VSM Futuro also included proposals that are part of the process, such as a supermarket and Kanban with the purpose of supplying raw material in a timely manner and requested, two Kaizen were represented representing the proposed Poka Yokes in order to expedite the process and reduce time in operations, see figure 5 .

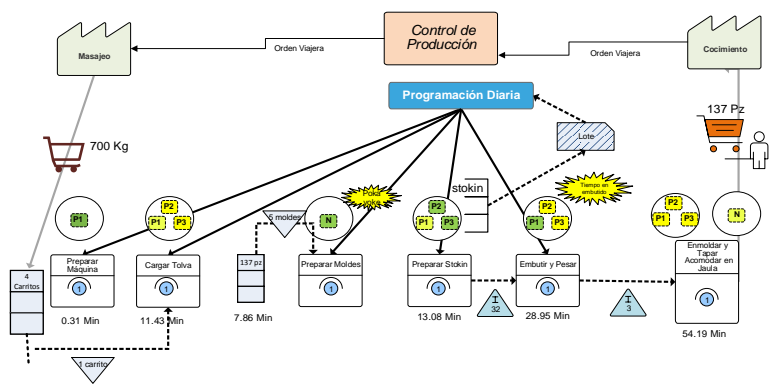

Figure 5 VSM Future of the Smoked Sausage Process

Analysis of Improvements in the Sausage Mixing and Sausage Process. The efficiency in the mixing and sausage of sausage was calculated in which a batch of $600 \mathrm{~kg}$ usually produces 2450 pieces in a time of 277 minutes, with the implementation of improvements and corrections of postures the production time of a batch at 179 minutes saving 98 minutes, see table 13.

\begin{tabular}{|l|l|l|l|}
\cline { 2 - 4 } \multicolumn{1}{c|}{} & \multicolumn{3}{c|}{ Mixing and Sausage Efficiency } \\
\cline { 2 - 4 } \multicolumn{1}{c|}{} & Min & Pieces & Lot \\
\hline Current & 277 & 2450 & $600 \mathrm{~kg}$ \\
\hline Improved & 179 & 2450 & $600 \mathrm{~kg}$ \\
\hline Saving & 98 & $\mathbf{3 5 . 3 7 \%}$ & \multicolumn{1}{|l}{} \\
\hline
\end{tabular}

Table 13 Efficiency Improvement in the Chorizo Mix and Sausage Process

Source: Self Made

As can be seen in the VSM Future, activities 1, 2, 6 and 7 were grouped in a single operation to what was called loading ingredients, using the tools Lean the supermarket and KanBan helps the operator manage the materials of a more efficient way since supplies will be supplied 2 times. Therefore, a single step was effectively achieved, leaving as a result loading ingredients activity 1,3 minutes the cycle time and activity 4 of 5 minutes the cycle time, see figure 6 .

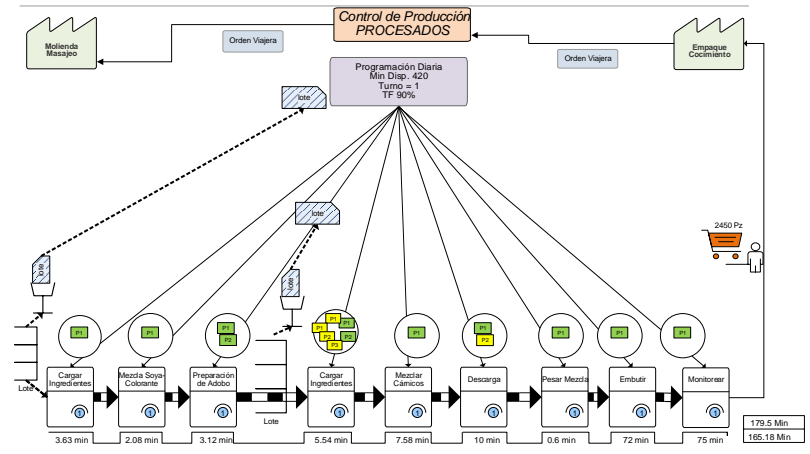

Figure 6 VSM Future of the Chorizo Mixing and Sausage Process

Analysis of Brine Process Improvements. The improvement of efficiency in the brine process considering that each batch has $300 \mathrm{Kg}$ of which 3001 ts of brine leave and normally during one shift 8 lots are processed in 347 min, with the implemented improvements of inferfon and postural correction in the operators its improvement is improved manufacturing time up to $21.6 \%$, see table 14 .

\begin{tabular}{|l|l|l|l|}
\cline { 2 - 4 } \multicolumn{1}{c|}{} & \multicolumn{3}{c|}{ Brine Efficiency } \\
\cline { 2 - 4 } \multicolumn{1}{c|}{} & Min & Pieces & Lot \\
\hline Current & 347 & 2400 lts & 8 \\
\hline Improved & 272 & 2400 lts & 8 \\
\hline Saving & $\mathbf{7 5}$ & $\mathbf{2 1 . 6 \%}$ & \multicolumn{1}{|c}{} \\
\cline { 1 - 4 } & & \multicolumn{3}{c}{}
\end{tabular}

Table 14 Efficiency Improvement in the Brine Process Source: Self Made

Ergonomic evaluation was performed again in the brine process, instructing the operator of the positions that must be adopted as can be seen in figure 7. A considerable reduction in ergonomic risks was achieved. The risk was lowered to a low level, in the same way in the evaluation through NIOSH it was lowered in the high risk levels to a low risk level.

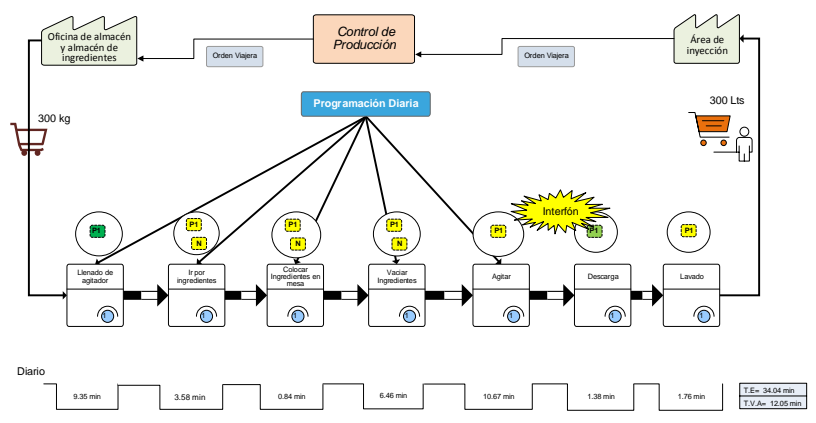

Figure 7 VSM Future of the Brine Process 


\section{Design of a Control Plan}

This tool helps the process to monitor each of the proposals made during its operations, determining the critical variables, as a result of the risks that exist are suffering from occupational diseases and injuries, the person responsible for each improvement and monitoring is designated as a method of control was proposed to make a checklist specifying the positions of the operator and the time it takes to perform it.

\section{Proposal Benefit Cost}

The cost of selling $1 \mathrm{Kg}$ of Tozinet is $\$ 87.00$ pesos of which $61 \%$ are costs and $39 \%$ profit, for each piece you earn \$33.39 pesos. The application of improvements in this process has a cost of $\$ 80,371.00$ pesos, but your investment would be recovered no later than 30 days considering that for each lot there are 54 more pieces earning $\$ 1,803.06$ pesos and normally 3 lots are produced daily, in 30 days $\$ 162,275.4$ pesos.

The daily production for the sausage mixing and sausage process is 2,450 pieces in 179 minutes, saving 100 minutes, which can be made up to 3 lots in the working day, multiplying the 3 lots by 2450 pieces by the price of the product in its presentation of $250 \mathrm{gr}$ is $\$ 16.00$ pesos, the company obtains $\$ 55,272.00$ pesos in profit for 3 lots, for 1 lot it gets $\$ 18,424.00$, considering that $53 \%$ of the sale price is cost and $47 \%$ profit, see table 15 .

\begin{tabular}{|l|l|r|}
\cline { 2 - 3 } \multicolumn{1}{c|}{} & \multicolumn{1}{c|}{ Proposal } & \multicolumn{1}{c|}{ Cost } \\
\hline \multirow{2}{*}{ Smoked Sausage Process } & Fiberglass Tape & $\$ 371.00$ \\
\cline { 2 - 3 } & Vertical Bucket Elevator & $\$ 80,000.00$ \\
\hline \multirow{2}{*}{$\begin{array}{l}\text { Chorizo Mix and Sausage } \\
\text { Process }\end{array}$} & Supermarket & $\$ 10,500.00$ \\
\cline { 2 - 3 } & Rotor change to equipment & $\$ 8,000.00$ \\
\cline { 2 - 3 } & Stainless steel shovel & $\$ 400.00$ \\
\hline Brine Process & 2 Interphone & $\$ 1,798.00$ \\
\hline
\end{tabular}

Table 15 Cost of proposals

To complement this study, an investigation was carried out to determine the expense that can be presented to an organization if the human factor is injured by any anomaly in its working life, see table 16.
González, (2015) mentions what cost is generated at a company for a disability to its worker is $\$ 209.00$ pesos considering that it is increasing over the years, while Banda, (2016) comments that the average cost for an accident at work is 200 thousand pesos, this will depend on the degree of physical damage that the worker is caused, on the other hand a carelessness can cause until death that according to (Álvarez, 2016) the obligation of the employer towards the family of the deceased is to pay compensation of 5,000 days of minimum wage, corresponding to 350,500 pesos, which are borne by the IMSS if the employee was insured, as established in Federal Labor Law in its article 502.

\begin{tabular}{|l|r|}
\hline \multicolumn{2}{|c|}{ Cost } \\
\hline Inability & $\$ 209.00$ \\
\hline Accident & $\$ 200,000.00$ \\
\hline Death & $\$ 350,000.00$ \\
\hline
\end{tabular}

Table 16 Cost of risks

\section{Acknowledgments}

The work team thanks all the participants for their interest and collaboration during the data collection. Thanks also to the university (Instituto Tecnológico de Sonora) for its support and facilities for the development of the project, this publication was funded by PFCE2019.

\section{Conclusions}

Based on the study and results of the Lean Ergonomics project applied to the different processes, the objective of increasing efficiency is achieved through Lean tools and ergonomic evaluations, improving on average $32 \%$ the operating times of each process, in turn It decreases and / or eliminates the level of risk of each activity to be carried out, allowing the operator to work in appropriate conditions and do his job in a safe way. Implementing the improvements has a cost, however, not attending to the needs of the process and the human factor generates accidents, diseases that lead to days of disability and even death, causing a higher cost for the organization and damage to the operator. Recent studies (Bertolini et al., 2013; Montero, 2016; Vinodh \& Joy, 2012) co-report that Lean Manufacturing is a system that focuses on the reconfiguration of manufacturing systems, tries to offer the highest possible value to customers with The least use of resources of all kinds, has its origin in the Toyota production system and consists of a method to systematically reduce waste.

LÓPEZ-ACOSTA, Mauricio, GARCÍA-VILCHES, Susana, VELARDE-CANTÚ, José Manuel and CHACARA-MONTES, Allán. Implementation of the lean ergonomics approach to process performance improvement. Journal of Microfinance Planning and Control. 2019 
In addition (Alpenberg and Scarbrought, 2016; Arezez et al, 2014; Dotoli, 2015) mention that this approach has become very popular among manufacturers, services and large commercial areas. Today, it is the best-known method for industrial improvement and acts at work through a set of group activities that pursue the benefit of the organization.

It is very important to follow up on the improvements and proposals made, as well as adopt the Lean culture in all the processes of the company. It is also highly recommended that the operator carry out the proposals for improvement on the postures that must be corrected since they have a high frequency of realization, in order to avoid injuries, fatigue, and disorders that may arise from performing their activities with erroneous positions., and thereby prevent the detonation of skeletal muscle disorders.

The key factors that can be supported are cost, quality, delivery, safety and morale, through simplified thinking that will help reduce costs, require less labor, increase product development, it will achieve better quality and generate huge profits, (Thurston and Ulmer, 2016).

It is recommended and important that employees be trained about the Lean Ergonomics philosophy so that they understand it, know how to carry it out and integrate it as part of the process.

According to Arce, Romero, \& Leon, (2017) Lean tools and practices have provided companies with significant help to meet the waste challenge, therefore, it has been possible to promote productivity and other key performance indicators. There are several cases of (Abuthakeer et al., 2010; Bertolini et al., 2013; Chong et al., 2013; Kumar et al., 2016; Lacerda et al., 2016) where they have reported positive results after implementation, how to shorten delivery times, reduce inventories of work in progress, increase the value-added relationship and among others.

It is necessary to follow up with the established control plan and its proposed frequency, since this tool is new for organizations and its implementation requires changes which are required to be monitoring until the process flows.

\section{References}

Abuthakeer, S., Mohanram, P. V., \& Kumar, G. (2010). Activity based costing value stream mapping. Lean Thinking, 52-64.

\author{
Álvarez, S. (11 de Abril de 2016). Revista \\ Manufactura. Obtenido de \\ http://www.manufactura.mx/gestion/2016/04/1 \\ 1/el-costo-de-los-accidentes-en-las-plantas- \\ industriales
}

Alpenberg, J., \& Scarbrough, P. (2016). Exploring communication practices in lean production. Journal of Business Research, 49594963.

Arce , A., Romero, L., \& Leon, J. (2017). Ergonomic Value Stream Mapping: A Novel Approach to Reduce Subjective Mental Workload. ResearchGate.

Arezes , P., Dinis , J., \& Alves , A. (2014). Workplace ergonomics in lean production environments: A literature review. Work: a journal of prevention, assessment and rehabilitation, 57-70.

Banda, L. (1 de Noviembre de 2016). Diario de Queretaro. Obtenido de https://www.diariodequeretaro.com.mx/local/cu esta-en-promedio-200-mil-cada-accidentelaboral-434835.html

Bertolini , M., Braglia, M., Romagnoli, G., \& Zammori, F. (2013). Extending value stream mapping: the synchro-MRP case. International Journal of Production Research, 5499-5519.

Cirjaliu, B., \& Draghici, A. (2016). Ergonomic Issues in Lean Manufacturing. ELSEVIER ScienceDirect, 105-110.

Cullinane, S., Bosak, J., Flood, P., \& Demerouti, E. (2014). Job desing under lean manufacturing and the quality of working life: a job demands and resources perspective. The International Journal of Human Resource Management, 29963015 .

Dos Santos, Z., Vieira, L., \& Balbinotti, G. (2015). Lean manufacturing and ergoomic working conditions in the automotive industry. Elsevier, 5947-5954. 
Dotoli, M., Epicoco, N., Falagario, M., Costantino, N., \& Turchiano, B. (2015). An integrated approach for warehouse analysis and optimization: a case study. Computers in Industry, 56-69.

González, J. (15 de Octubre de 2015). Revista Digital Lider Empresarial. Obtenido de https://www.liderempresarial.com/negocios/cua nto-cuesta-un-accidente-de-trabajo/

Jarebrant, C., Winkel, J., Hanse, J., Mathiassen, S., \& Öjmertz, B. (2015). ErgoVSM: A Tool for Integrating Value Stream Mapping and Ergonomics in Manufacturing. Human Factors and Ergonomics in Manufacturing \& Service Industries, 1-14.

Jon, W., Karlin, J., \& Kerk, C. (2007). Integrated lean thinking \& ergonomics: Utilizing solutions for a productive workplace. MHI Material Handling Industry of America.

Kasper, E. (2017). Integrating Work Environment Considerations Into Lean and Value Stream Mapping. Technical Knowledge Ctr Denmark.

Kim, I.-J. (2017). The Function of Ergonomics in Lean Manufacturing Design and Control. Journal of Ergonomics.

Kumar, M. (2014). Development and validation of drivers for barriers to and stakeholders of green manufacturing. Birla institute of technology and science.

Kumar, D., Shivashankar, K. R., \& Rajeshw, G. S. (2016). Application of value stream mapping in pump assembly process: a case study. Industrial Engineering \& Management, 2-11.

Lacerda , A. P., Xambre , A. R., \& Alvelos, H. M. (2016). Applying value stream mapping to eliminate waste: a case study of an original equipment manufacturer for the automotive industry. nternational Journal of Production Research, 1708-1720.

Màrquez, M. (2012). Los sistemas de producciòn y la ergoomìa: reflexiones para el
Monroe, K., Fick, F., \& Joshi, M. (2012). Successful integration og ergonomics into continuos improvement initiatives. World congress on Ergonomics - Designing a sustainable future, 1622-1624.

Morse, A. (2014). Evaluating the impact of Lean on Employee Ergonomics, Safety and Job Satisfaction in Manufacturing. Louisiana State University, LSU Digital Commons.

Montero, R. (2016). Relación entre el Lean Manufacturing y la seguridad y salud ocupacional. Salud de los Trabajadores, vol. 24, 133-138.

Mulyati, G., Muharom, M., \& Suharno. (2015). An implementation of lea-ergonomic approach to reduce ergonomic parameter waste in the manufacture of crackers. KnE Life Sciencies, 21-24.

Peralta, C., Lermen, F., Soares, M., Lunardi, P., \& Basso, C. (2017). Lean Manufacturing and ergonomics: a systematic literature review. Journal of lean systems, 22-36.

Prins, Christian. 2004. A simple and effective evolutionary algorithm for the vehicle routing problem. Computers \& Operations Research, volume 31, issue 12, pages 1985-2002.

Solìs, R., \& Madriz, C. (2009). Aplicaciòn de ergo-lean manufacturing en el anàlisi de valor. Tecnologìa en Marcha, 24-28.

Srinivasa, R., \& Malay, N. (2016). A case study on implementing lean ergonomic manufacturing systems (LEMS) in an automobile industry. IOP Conference Series: Materials Science and Engineer.

Thurston, J., \& Ulmer, J. (2016). The Principles of Lean Manufacturing. Franklin Business \& Law, 57-71.

Vinodh, S., \& Joy, D. (2012). Structural Equation Modelling of lean manufacturing practices. International Journal of Production Research, 1599-1607. 
Yang, M., Hong, P., \& Modi, S. (2011). Impact of lean manufacturing and enviromental management on business perfomance: An empirical study of manufacturing firms. International Journal of Production Economics, 251-261

\section{Annexes}

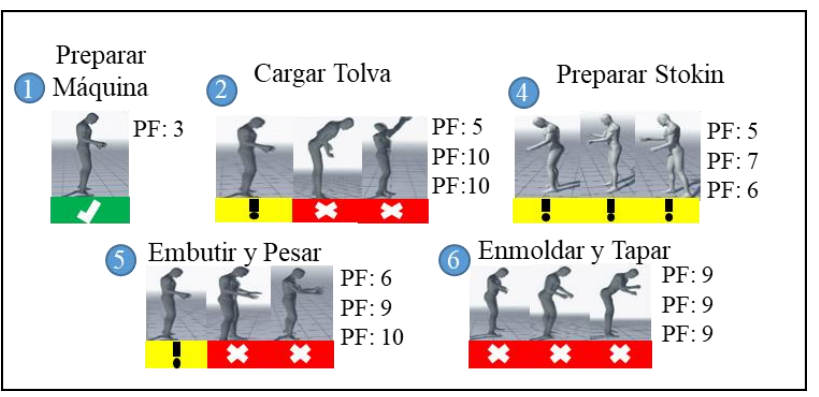

Annexes 1 Ergonomic evaluation positions of the Smoked Sausage process with REBA Method

Source: Self Made

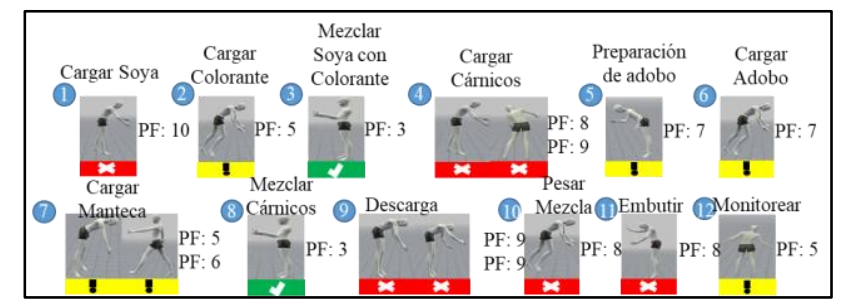

Annexes 2 Ergonomic evaluation positions of the Chorizo Mixing and Sausage process with REBA Method Source: Self Made

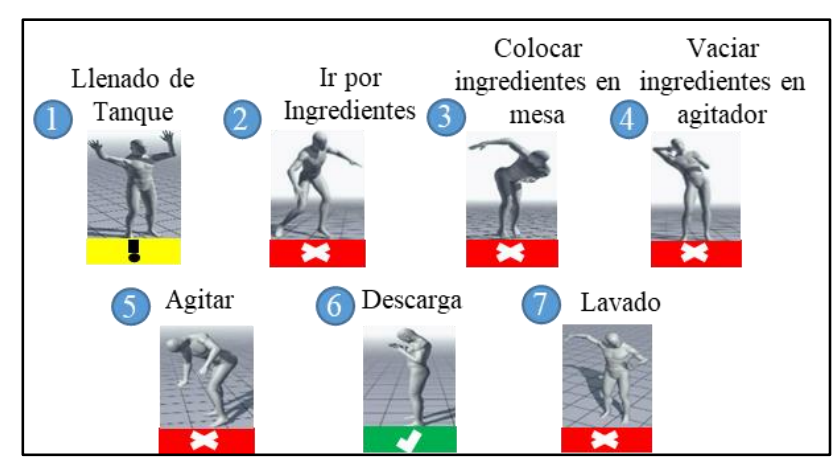

Annexes 3 Ergonomic evaluation positions of the Brine process with REBA Method Source: Self Made 